\title{
RESENHA
}

\section{A CULTURA DE CONSUMO NA PERSPECTIVA DE ROBERTA SASSATELLI: UM OLHAR HISTÓRICO E SOCIOLÓGICO}

\author{
THE CULTURE OF CONSUMPTION FROM \\ THE PERSPECTIVE OF ROBERTA SASSATELLI: \\ A LOOK AT HISTORICAL AND SOCIOLOGICAL
}

Felipe da Luz Colomé*

SASSATELLI, Roberta. Consumer culture. History, theory and politics. London: Sage, 2007.

Na obra que é objeto desta resenha, a autora visa discutir sobre as práticas, discursos e instituições que tratam e caracterizam a "cultura de consumo". Desta forma, ela aborda a "cultura de consumo" como sendo fruto de um processo histórico que atualmente organiza as relações entre as pessoas e os objetos. Partindo do pressuposto que os objetos materiais acompanham a existência humana em distintas culturas e sociedades ao longo da história, Sassatelli (2007) busca delinear quais seriam os traços distintivos do consumo no cenário contemporâneo e suas consequências na organização da vida social. Assim, através do resgate e contraste de diversas perspectivas analíticas sobre a "cultura de consumo" e os discursos e práticas que lhe sustentam, a autora problematiza como estão construídos os diferentes discursos que naturalizam a figura do "consumidor" nas sociedades de mercado, ou aqueles que buscam de diferentes formas legitimar ou deslegitimar as relações de consumo no cenário capitalista.

O livro é estruturado de modo a oferecer aos leitores uma discussão a partir de um ponto de vista histórico e sociológico sobre o

\footnotetext{
* Mestre em Ciências Sociais e Doutorando no Programa de Pós-Graduação em Sociologia da Universidade Federal do Rio Grande do Sul - UFRGS, Porto Alegre, Brasil; e-mail: flcolome@, hotmail.com

242| Século XXI, Revista de Ciências Sociais, v.3, nº 2, p.242-251, jul./dez. 2013 ISSN: 2236-6725
} 
fenômeno em questão, evidenciando as dicotomias e ambivalências presentes tanto nas interpretações leigas e nos discursos científicos. Desta maneira, os capítulos estão divididos em três partes, organizados em torno de três grandes dicotomias: a dicotomia produção versus consumo, a dicotomia racionalidade versus irracionalidade e por fim a dicotomia liberdade versus opressão. Embora, de acordo com a autora, a maior parte da obra pretende mostrar como o consumo desafia estas dicotomias e envolve outros padrões mais complexos de relação, elas ajudam a compreender a história, teorias e políticas relacionadas à "cultura de consumo" contemporânea.

Na primeira parte do livro a autora realiza o mapeamento histórico dos diferentes fatores, espaciais e temporais, que historicamente articularam o desenvolvimento da "cultura de consumo" no contexto ocidental e com isso fornecer uma "leitura cultural" das grandes transformações sócio-econômicas e geopolíticas imbricadas à ela. $\mathrm{Na}$ segunda parte, Sassatelli discute sobre as principais abordagens teóricas que tentaram modelar a agência do consumidor. Já a terceira parte do livro é dedicada à considerar as dimensões políticas da cultura de consumo, observando o tema da representação e intermediação e o papel da publicidade, e ainda à discutir as noções de "comoditização" e "de-comoditização" como um terreno contestado no qual os atores poderiam negociar as visões hegemônicas sobre identidade e escolha. Por fim, a autora discute nesta parte, os temas que dizem respeito à globalização, localização e consumo alternativo.

Muitas reflexões têm sido realizadas, notadamente a partir da década de 1950 nas Ciências Sociais, sobre a ascensão do fenômeno intitulado de cultura de consumo e seus congêneres como sociedade cultura de consumo ou sociedade de consumo. Grande parte destas reflexões ${ }^{2}$ se assentam na noção central de que estaríamos presen-

\footnotetext{
${ }^{1}$ De acordo com Sassatelli (2007, p.139), a palavra "commoditização" denota uma construção social e econômica particular das coisas: é o processo através do qual as coisas são produzidas e comercializadas como commodities.

${ }^{2}$ São exemplos desta perspectiva as abordagens de Baudrillard (1995), Bauman (1999).

243| Século XXI, Revista de Ciências Sociais, v.3, nº 2, p.242-251, jul./dez. 2013 ISSN: 2236-6725
} 
ciando nas sociedades contemporâneas uma fase distintiva do capitalismo caracterizada pela primazia do consumo. Marcadas por uma ênfase na denúncia sobre as mazelas geradas pela sociedade centralizada em torno do consumo, como seria o caso do individualismo que chegaria em seu ápice, tais análises localizavam uma ruptura na modernidade na qual a lógica de organização social migraria da produção para o consumo.

Conforme Sassatelli (2007), não obstante as diferentes interpretações sobre os impactos da cultura de consumo ou da sociedade de consumo nas diferentes instâncias sociais, o fio condutor que guiou grande parte destas análises era orientado por uma crítica ao que seria percebido como uma crescente e incontrolável paixão pelo acúmulo de objetos materiais, que causaria um processo de descontentamento pessoal e de desengajamento com as causas atinentes à esfera pública. Nestes termos, durante um período considerável muitas destas perspectivas compartilhavam a noção de que a cultura de consumo e suas práticas que seriam caracterizadas nas sociedades industrializadas por sua lógica massificada, eram o fruto tardio da revolução industrial que emergiu no começo do século XX.

Contudo, a autora nos mostra que antes mesmo das discussões sobre o que tem sido percebido como a conformação da cultura de consumo, diferentes autores ${ }^{3}$ já haviam demonstrado o importante papel do consumo nas sociedades ocidentais, seja analisando os padrões de consumo gerados pela ascensão da burguesia no cenário europeu ou a influência dos regimes monárquicos e suas lógicas de consumo. Sassatelli (2007, p.14) destaca que as pesquisas históricas e sociológicas contemporâneas ${ }^{4}$ têm revisado as compreensões de que a "cultura de consumo" seria um epifenômeno da revolução industrial, avaliando que o consumo desempenhou um papel importante no desenvolvimento do capitalismo.

Nestes termos, citando o trabalho clássico de Sombart (2009), a autora ressalta como ele antecipou tal perspectiva ao realizar um estudo sobre a ascensão do consumo de luxo desde o período do me-

${ }^{3}$ Como é o caso de Sombart (2009), Simmel (1957) e Elias (1994).

${ }^{4}$ De acordo com Sassatelli, é o caso dos estudos desenvolvidos por McKendrick; Brewer e Plumb (1982), Campbell (2001) e De Vries (1975).

244| Século XXI, Revista de Ciências Sociais, v.3, nº 2, p.242-251, jul./dez. 2013 ISSN: 2236-6725 
dievo. Ao considerar os bens de luxo e das commodities coloniais, juntamente com o florescimento de novos valores e relações sociais, Sombart revela como estes fatores contribuíram para a emergência de um novo modo de vida. Nesta ótica, Sassatelli (2007, p.30) nos mostra como o estudo de Sombart foi importante para a percepção de que estes bens e relações foram fundamentais para uma variedade de espaços e instituições que têm funcionado, desde pelo menos o século XVII, como motores para a eclosão da cultura de consumo.

Assim, em contraposição às interpretações economicistas 5 , alguns autores clássicos da sociologia como é o caso de Sombart (2009), Simmel (1971), e mesmo o economista Veblen (1987), já traziam novas luzes para as interpretações científicas sobre o consumo, salientando aspectos que dizem respeito ao papel da competição por status entre as classes, o papel da moda e do luxo, e a constituição das práticas de consumo através de lógicas culturais, em contraposição às interpretações do consumo como mera realização de vontades individuais.

Valendo-se de estudos sobre o papel do consumo e dos valores a ele associados em um contexto que antecedeu à revolução industrial, e abordagens que evidenciam as raízes históricas da cultura de consumo, da construção social da categoria "consumidores", Sassatelli considera que a história da cultura de consumo é tanto a história de uma grande transformação material e institucional, quanto das transformações oriundas de novas orientações culturais em relação à economia, como é o caso dos pressupostos da economia clássica. Conforme ela, especialmente a partir do século XVIII, o consumo passou a ser problematizado como uma atividade que é relevante em si mesma, bem como é crucial na definição das relações sociais e das identidades. Desde então, tanto atores dos mercados, quanto atores políticos contribuíram para produzir o "consumidor" como uma dominante, mesmo que constantemente contestada e nuançada, identidade social.

Evidenciando os estudos realizados por autores como Appa-

\footnotetext{
${ }^{5}$ Conforme Sassatelli a modelagem do consumidor realizada pela teoria econômica neoclássica postula este agente como um ator instrumentalmente racional que visa maximizar a utilidade e minimizar os custos. Contudo, no curso de século XX, a economia neoclássica encontrou algumas dificuldades significativas na sua tentativa de compreender e modelar o consumo como uma decisão puramente instrumental e racional e com isso tentou incorporar em seu modelo teórico variáveis sociais, sob as rubrica por exemplo do consumo conspícuo de Veblen.
}

245| Século XXI, Revista de Ciências Sociais, v.3, nº 2, p.242-251, jul./dez. 2013 ISSN: 2236-6725 
durai(1991) e Mukerji (1983), que esclarecem como os fluxos globais de commodities e de conhecimento, e em especial dos bens coloniais e dos valores materialistas, têm desempenhado um papel importante no desenvolvimento da cultura de consumo no ocidente, Sassatelli (2007, p.25) destaca que um processo de moralização contínua acompanhou a percepção sobre os bens de consumo em diversos contextos históricos, e os lugares e práticas que parecem definir diferentes períodos da história do consumo, desde os primeiros momentos da modernidade até o presente.

Desta forma, a autora salienta como estes estudos contribuíram para mostrar as significantes tendências históricas que cooperaram para o advento de novos padrões de consumo, de novas atitudes em relação ao uso e aproveitamento de bens, antes do surgimento da revolução industrial. Desta forma, de acordo com Sassatelli, na atualidade, sociólogos, antropólogos e historiadores tendem a favorecer explicações multi-fatoriais sobre a gênesis e o desenvolvimento da chamada cultura de consumo. Portanto, eles têm abandonado a utilização de um modelo linear de desenvolvimento, em favor de compreensões sobre as múltiplas geografias e temporalidades de uma variedade de consumo de bens e de valores.

Entre estas novas compreensões não lineares sobre o consumo, Sassatelli (2007, p.37) considera que a ênfase na função simbólica das práticas de consumo, onde os bens são concebidos como elementos materiais através dos quais os atores sociais reproduzem significados culturais que estruturam o espaço social, constitui-se em uma perspectiva bastante difundida nas Ciências Sociais, principalmente através dos trabalhos de Bourdieu (2007) e Douglas e Isherwood (2006). Os trabalhos desses autores, ao seu turno, deram origem à novas perspectivas que revisam parcialmente suas abordagens. Deste modo, de acordo com Sassatelli (p.77), uma rica literatura tem sido produzida nas últimas duas décadas, tanto na sociologia quanto na antropologia, centrando-se na organização do consumo em uma variedade de espaços e ocasiões, ressaltando a sua diversidade. Assim, autores como De Certeau (1998), McCracken (2010) e Miller (2002) têm concebido o consumo como um processo ativo 
de apropriação que ocorre de acordo com diferentes rituais. Os trabalhos de Miller, por exemplo, mostram que o consumo pode conter potencial subversivo e que pode até mesmo ser usado para questionar o capitalismo. Neste sentido, Sassatelli destaca que a agência do consumidor, ou seja, a margem de manobra que os atores sociais têm quando eles agem como consumidores, tem se tornado uma questão fundamental nos estudos atuais de consumo.

Portanto, a autora sublinha que através destas novas perspectivas, o consumo pode ser visto como um processo muito mais ativo e menos impessoal do que algumas teorias postulavam. Através da noção de apropriação, por exemplo, a sociologia cultural tem demonstrado que o consumo é baseado em relações pessoais e instituições sociais que transformam as commodities e seus significados. Citando a investigação realizada por Kopytoff (1991), que indica que o processo de comoditização é um contestado e reversível processo social, Sassatelli pondera que o consumo por sua vez, pode ser percebido também como um processo de re-significação das commodities, no qual os agentes durante as práticas de consumo podem personalizar as mercadorias, codificá-las com base em suas experiências vividas e socializá-las através de encontros sociais de vários tipos.

Ademais, conforme a autora, estas novas abordagens têm problematizado a forma como os atores políticos e do mercado interagem para moldar os contextos de consumo, considerando que a diferença funcional entre a política e a economia, que é tomada como uma garantia em muitas sociedades contemporâneas, é historicamente fundamentada em um acordo tácito. Deste modo, estas novas abordagens, em especial os estudos no âmbito da sociologia cultural e da sociologia econômica, têm ajudado a desconstruir as fronteiras e falsas dicotomias entre a política e a economia.

$\mathrm{Na}$ atualidade, a autora considera que juntamente com a ascensão ao redor do mundo de diferentes discursos e iniciativas de consumo alternativo, como é o caso das iniciativas de campanhas para o consumo crítico e responsável, do Comércio Justo, do movimento de Slow Food, de alimentação orgânica, entre outros, é possível observar um esforço sociológico para a compreensão das poten- 
cialidades e limites da ação política por meio do consumo. Levando em conta que a utilização dos bens com a finalidade de intervenção no campo possui uma longa história ${ }^{6}$, estando presente em diversos contextos na modernidade, Sassatelli (2007, p.170) considera que estamos testemunhando um momento com características peculiares. A expansão global do capitalismo, e suas consequências como a poluição, a desigualdade de acesso à bens de consumo e informação e o fosso cada vez maior entre o Norte e o Sul, são os contornos mais gerais que têm pautado o discurso crítico das iniciativas de consumo alternativo, que também dirigem suas críticas em grande parte contra as corporações econômicas multinacionais.

Conforme a autora, não obstante o potencial para a participação política através das práticas de consumo ser destacado por diversos autores ${ }^{7}$, trata-se de um tema controverso. Para Sassatelli (2007), muitas das noções sobre a agência do consumidor, como é o caso da noção de soberania, ainda estão fortemente vinculados com os pressupostos da economia neoclássica, o que pode inviabilizar as tentativas de politização na medida em que elas estão baseadas em uma visão atomística da escolha dos atores no mercado e uma visão idealizada do funcionamento dos mercados capitalistas. Por outro lado, ela pondera que muitos estudos têm demonstrado que estas novas iniciativas, como é o caso do comércio justo, que compreendem a figura do consumidor também como um sujeito moral e político podem contribuir para a constituição de novos repertórios para a ação política.

Criticando algumas interpretações que celebrariam a ascensão da figura do cidadão-consumidor, como a de Beck (1992), Sassatelli considera que seria equivocado atribuir um sentido intrinsecamente político para a escolha do consumidor ou considerar equivalente à formas tradicionais de ação política, visto que muitas

\footnotetext{
${ }^{6}$ Conforme Hilton (2003) o consumo como estratégia de intervenção política foi utilizado em diversos contextos históricos, como no caso da Inglaterra no século XIX onde foram realizadas manifestações populares contrárias a lei chamada Corn Law, que elevou consideravelmente o preço de produtosbásicos como o pão. Outros exemplos seriam a utilização dos bens como estratégias políticas materializados no processo de independência dos Estados Unidos e da Índia, como destacam Micheletti $(2002,2003)$ e Bayly (1991).

${ }^{7}$ Micheletti (2002, 2003), Sassateli (2006, 2007), Stolle, Hooghe \& Micheletti (2005) Sorensen (2005), Hilton (2003), Canclini (1995).

248| Século XXI, Revista de Ciências Sociais, v.3, n² 2, p.242-251, jul./dez. 2013 ISSN: 2236-6725
} 
das práticas que estão sob o guarda-chuva do consumo alternativo podem ser conduzidos por consumidores que têm em mente outros significados e objetivos que os estritamente políticos.

De modo geral, na obra aqui resenhada, Sassatelli realiza uma interessante discussão sobre a cultura de consumo a partir de diversas perspectivas e ângulos, as suas origens, paradoxos, continuidades, rupturas e conformação nos dias atuais. Neste sentido, a socióloga explora as diferentes faces de um contestado processo histórico que originou a figura do consumidor e suas possibilidades de agência. Destacando as grandes ambiguidades das noções de "cultura de consumo" ela, vai buscar as raízes deste processo histórico e para isso traz à baila, diferentes elementos para a sua compreensão e, ainda, as implicações políticas de se conceber a cultura contemporânea como sendo dirigida pela "cultura de consumo".

Desta forma, buscando demonstrar através de uma vasta e rica bibliografia, a extensão e complexidade do fenômeno focalizado, a autora têm o mérito de realizar uma análise não simplificadora acerca das diferentes abordagens sobre o consumo e ao mesmo tempo oferecer ao leitor um panorama geral dos estudos sobre o consumo e a cultura de consumo. Portanto, a obra em questão constitui-se em uma leitura muito importante para os cientistas sociais e profissionais de áreas afins interessados nas discussões sociológicas sobre o consumo e a cultura de consumo contemporânea.

\section{REFERÊNCIAS}

APPADURAI, A. La vida social de las cosas. México: D. F: Grijalbo, 1991 BAUDRILLARD, J. A sociedade de consumo. Rio de Janeiro: Elfos, 1995. BAUMAN, Z. Globalização: As consequências humanas. Rio de Janeiro: Jorge Zahar, 1999.

BAYLY, C. Los origenes de la swadeshi (industria doméstica): Telas y sociedad indú,1700-1930. IN APPADURAI, Arjun. La vida social de las cosas. México, D. F: Grijalbo, 1991. 
BECK, U. Risk Society: Towards a New Modernity, London: Sage, 1992.

BOURDIEU, P. A distinção: crítica social do julgamento. Porto alegre: Zouk, 2007.

CAMPBELL, C. A ética romântica e o espírito do consumismo moderno. Rio de Janeiro: Rocco, 2001.

CANCLINI, N. G. Consumidores e Cidadãos: conflitos multiculturais da globalização. Rio de Janeiro: Ed. UFRJ, 1995.

De CERTEAU, M. A invenção do cotidiano. Petrópolis: Vozes, 1998.

DOUGLAS, M.; ISHERWOOD, B. O mundo dos bens: para uma antropologia do consumo. Rio de Janeiro: Ed UFRJ, 2006

ELIAS, N. O processo civilizador. Rio de Janeiro: Jorge Zahar, 1994.

De VRIES, J. Peasant demand patterns and economic development: Friesland, 1550-1750. In: PARKER, W. N. and JONES, E. L. (Eds.). European Peasants and their Markets: Essays in Agrarian Economic History, Princeton: Princeton University Press, 1975.

HILTON, M. Consumerism in Twentieth-century britain: the search for a historical movement. Cambridge, Cambridge university press, 2003.

KOPYTOFF, I. La biografía cultural de las cosas: La mercantilización como proceso. IN APPADURAI, Arjun. La vida social de las cosas. México, D. F: Grijalbo, 1991.

SASSATELLI, R. Virtue, responsibility and consumer choice. Framing critical consumerism. In: BREWER, J. and TRENTMANN, F. (Eds.). Consuming Cultures, Global Perspectives. Historical Trajectories, Transnational Exchanges. Oxford: Berg, 2006

. Consumer culture. History, theory and politics. London: Sage, 2007.

SIMMEL, G. Fashion. In: . On Individuality and Social Forms. Chicago: Chicago University Press, pp. 294-323, 1971.

SOMBART, W. Lujo y capitalismo. Madrid: Ediciones Sequitur, 2009.

SORENSEN, M. Liberal Democratic Society and Political Consumerism: a Problematic Combination. In: Political Consumerism: Its motivations, power, and conditions in the Nordic countries and elsewhere. Proceedings from the 2nd International Seminar on 
Political Consumerism, Oslo August 26-29, 2005.

STOLLE, Dietlind; HOOGHE, Marc \& MICHELETTI, Michele. Politics in the supermarket: political consumerism as a form of political participation. International Political Science Review, Vol. 26, nº3, p.245-269, 2005.

MCCRACKEN, G. Cultura e consumo: novas abordagens a caráter simbólico dos bens e das atividades de consumo. Rio de Janeiro: MAUAD, 2010.

MCKENDRICK, N; BREWER, J; PLUMB, J. M. (Eds.). The Birth of a Consumer Society: The Commercialization of Eighteenth-Century England. Bloomington: Indiana University Press, 1982.

MUKERJI, C. From Graven Images: Patterns of Modern Materialism. New York: Columbia University Press, 1983.

MILlER, D. Teoria das compras: o que orienta as escolhas dos consumidores. São Paulo, Nobel, 2002.

VEBLEN, T. Teoria da classe ociosa: um estudo econômico das instituições. São Paulo: Nova Cultural, 1987. 